Int. J. Electrochem. Sci., 12 (2017) $2412-2428$

International Journal of

ELECTROCHEMICAL

SCIENCE

www.electrochemsci.org

\title{
Galvanic Corrosion Behavior of 907A/ Titanium Couple in Simulated Seawater
}

\author{
Xiaodong Zhang ${ }^{1}$, Xiaoqing $\mathrm{Du}^{2, *}$, Chao $\mathrm{Cai}^{3}$, Zhao Zhang, ${ }^{2, *}$ \\ ${ }^{1}$ MIUR, Naval University of Engineering, Wuhan 430033, China \\ ${ }^{2}$ Department of Chemistry, Zhejiang University, Hangzhou 310027, China \\ ${ }^{3}$ Department of Chemistry, Ningxia University, Yinchuan750021, China \\ *E-mail: eaglezzy@zju.edu.cn, amyzju88@163.com
}

doi: $10.20964 / 2017.03 .75$

Received: 3 January 2017 / Accepted: 29 January 2017 / Published: 12 February 2017

The corrosion behaviors of 907A and 907A/ titanium galvanic couple (GC) in seawater have been studied by using electrochemical impedance spectroscopy and electrochemical noise techniques in conjunction with scanning electron microscope method. The results show that, both the corrosion process of 907A and 907A / Ti GC can be divided into two stages but with different demarcation point, and the potential difference between $\mathrm{Ti}$ and 907A not only markedly accelerates the corrosion process of $907 \mathrm{~A}$ in $907 \mathrm{~A} / \mathrm{Ti} \mathrm{GC}$, but also possibly changes its corrosion mechanism. The electrochemical active energy $E_{a}$ derived from the corrosion noise has been first adopted to characterize the corrosion process of $907 \mathrm{~A}$ and $907 \mathrm{~A} / \mathrm{Ti} \mathrm{GC}$ in seawater, and it is found that the larger the $E_{a}$ value, the higher the corrosion rate.

Keywords: 907A/Ti; Galvanic corrosion; Electrochemical noise; Electrochemical impedance spectroscopy;

\section{FULL TEXT}

(C) 2017 The Authors. Published by ESG (www.electrochemsci.org). This article is an open access article distributed under the terms and conditions of the Creative Commons Attribution license (http://creativecommons.org/licenses/by/4.0/). 